\title{
THE PASSAGE OF DRUGS INTO HORSE SALIVA AND THE SUITABILITY OF SALIVA FOR PRE-RACE TESTING
}

\author{
MARIAN W. HORNER
}

\section{Racecourse Security Services' Laboratories, P.O. Box 15, Snailwell Road, Newmarket, Suffolk CB8 7DT}

\section{Introduction}

If pre-race testing were to be introduced in this country we should need to decide first on which is the best sample to use for testing. Witherington has already discussed in some detail the advantages and disadvantages of urine, blood and saliva for this purpose, and of these saliva seems to be the most promising. Its only real disadvantage is the very small size of the sample obtained.

Although saliva has been used widely in the past for drug screening in the horse, remarkably little work has been done to discover which drugs pass into horse saliva from the blood stream and what factors are involved. The usefulness of saliva for pre-race testing cannot be assessed without knowing this.

\section{STUDY OF THE TRANSPORT OF DRUGS INTO SALIVA}

\section{Methods of Saliva Collection}

Figure 1a shows how a saliva sample is taken at the racecourse by swabbing out the horse's mouth with a gauze pad held in forceps. This usually only produces 2 to $3 \mathrm{ml}$ of saliva.

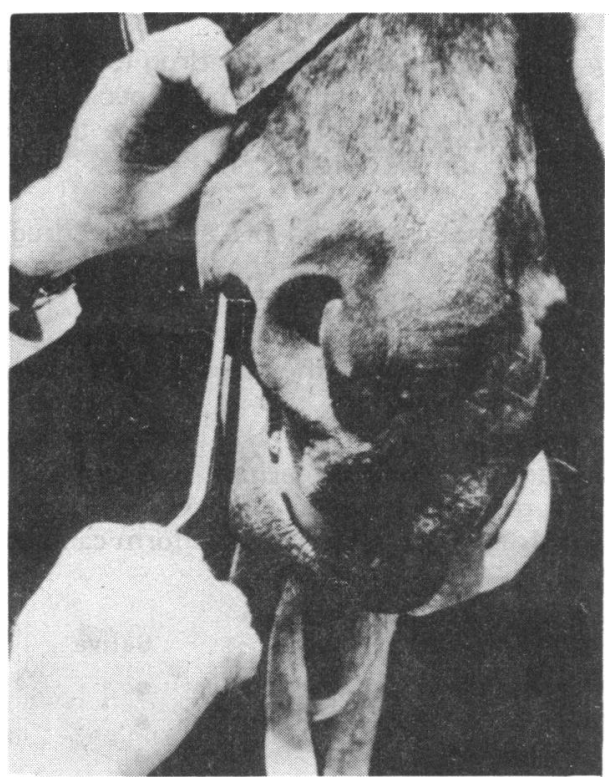

However, work at these laboratories has been facilitated by use of ponies with explanted parotid papillae. The papilla is the site of the opening of the parotid salivary duct on the inside of the cheek, and in each of these ponies a surgical operation has been performed which brings one papilla through to the outside of the cheek, so that pure parotid saliva can easily be collected.

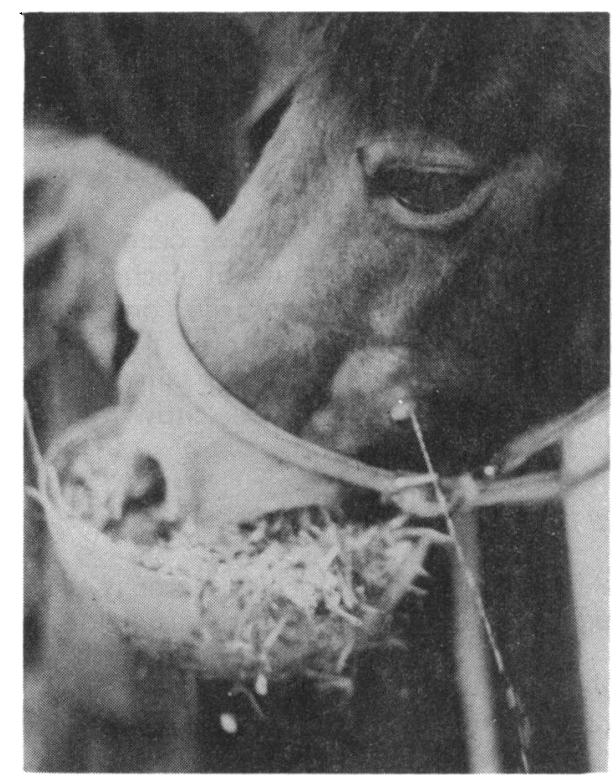

Fig. 1. Methods of obtaining horse saliva
a. Swabbing.
b. Production of saliva from an explanted parotid papilla. (photographs, M. S. Moss)

Figure 1b shows how saliva is produced from the papilla. The parotid is the largest salivary gland, and it produces $15-20$ times the volume of saliva secreted by the mandibular gland (Colin, 1886). Saliva does not flow from the papilla when the animal is resting, but when the pony eats it is produced in powerful jets $-a$ jet for each chewing movement - at rates of up to $40 \mathrm{ml} / \mathrm{min}$ or more, so that samples can be collected at precise times merely by giving food and standing by with a collecting pot. The collecting period is normally $30 \mathrm{sec}$ but sometimes has to be longer when the salivary flow rate is low, as happens when the pony is mainly chewing on the opposite side of the mouth (Bernard, 1856; 
The operation was performed on three ponies in the years 1971 to 1973; they have remained in excellent health since then, in spite of the regular loss from the body of large amounts of electrolytes in the saliva. Decreased urinary excretion of electrolytes must compensate for the loss, since the serum electrolyte concentrations have stayed normal.

One of the ponies also has an explanted mandibular papilla. The secretion from this is continuous and very slow; it is slightly increased during feeding but even then only produces about $1 \mathrm{ml}$ saliva per minute.

For measurement of the $\mathrm{pH}$ of parotid saliva it was necessary to cannulate the parotid duct and collect the saliva under liquid paraffin, since parotid saliva is poorly buffered and on exposure to air rapidly loses $\mathrm{CO}_{2}$, causing the $\mathrm{pH}$ to rise.

\section{Factors Controlling Drug Transport into Saliva}

So far 11 different drugs have been given to these ponies and the concentrations of each drug in blood plasma and parotid saliva have been compared. The aim of this work has been to discover the factors which control the passage of drugs into saliva. These experiments and the work of others show that there are several.

\section{lonising Properties of the Drug}

The first and most important factor is the nature of the drug itself, whether it is neutral, acidic or basic.

Neutral drugs. It seems clear that only the un-ionised form of the drug can cross into saliva, so that neutral drugs are found there in the same concentrations as in the plasma.

For the first saliva experiments in these laboratories a neutral drug, chloral hydrate, was used (Alexander, Horner et al., 1967). However, instead of collecting saliva briefly, immediately after collecting blood, as is done now, a cannula was inserted into the parotid duct and saliva was allowed to flow through the cannula to accumulate in a sample bag, the pony being free to feed if and when it chose; so it was impossible to compare the plasma and saliva concentrations precisely, although they were very similar. The chloral hydrate $(170 \mathrm{mg} / \mathrm{kg})$ was given orally and reached a concentration of $17 \mu \mathrm{g} / \mathrm{ml}$ plasma one hour later; at about this time the saliva concentration was $19 \mu \mathrm{g} / \mathrm{ml}$. Two hours after the dose it had practically disappeared from both fluids.

Most of the chloral hydrate was rapidly metabolised to another neutral compound, trichloroethanol, which was also found in approximately the same concentration in saliva and plasma and was present up to 24 hours after the dose.

Figure 2 shows a more recent experiment with a neutral drug. This is part of a study on ethanol metabolism which is currently in progress at these laboratories. The average saliva to plasma concentration ratio is close to 1.0 . The same ratio had been shown for ethanol in man (Linde, 1932).

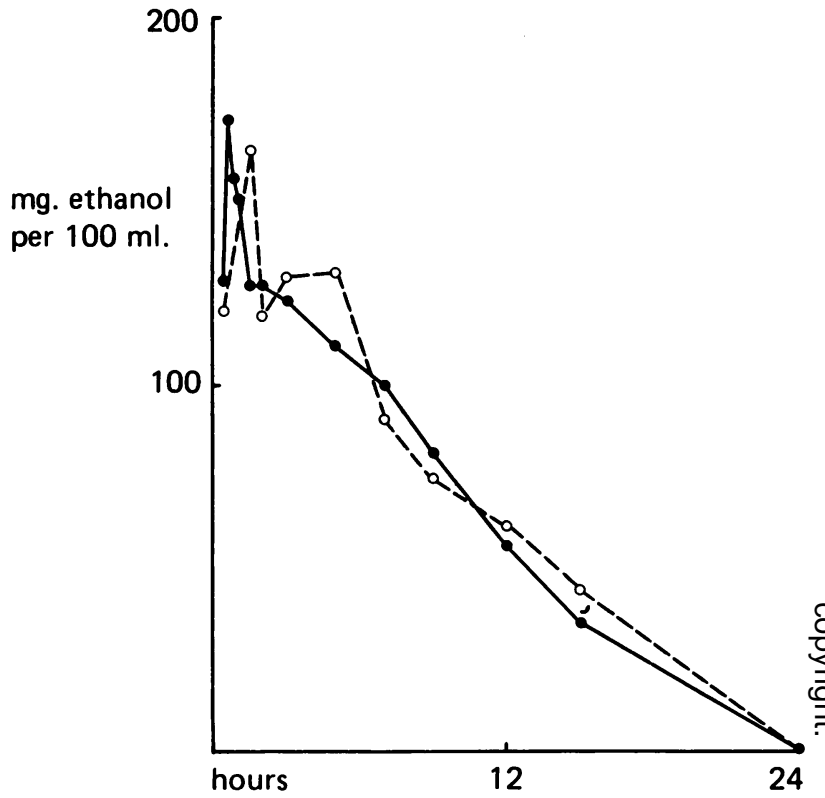

Fig. 2. Concentrations of ethanol in horse plasma ( $(\theta)$ and parotid saliva (O) after oral administration $(1.14 \mathrm{mg}$ ethanol $/ \mathrm{kg}$ ).

lonising drugs. However, when a drug ionises, as many do, its transfer is more complicated, especially when the $\mathrm{pH}$ of the two fluids is different, because the extent to which the drug ionises depends on the $\mathrm{pH}$.

Supposing that at plasma $\mathrm{pH}$ an acidic drug is $50 \%$ ionised, so that for every un-ionised molecule, $\bullet$, there will be one molecule in the ionised form, $\circ$. At the higher $\mathrm{pH}$ of horse saliva it may be two-thirds ionised, giving two molecules of the ionised form to each unionised molecule.

When equilibrium is reached between saliva and plasma there will be the same concentration of the unionised drug in each, because this form can pass across freely.

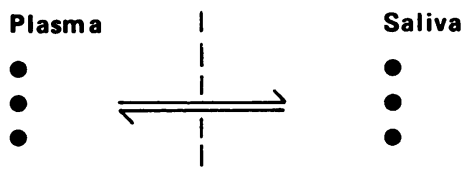


Although the ionised molecules cannot themselves cross, additional un-ionised molecules will also pass across into the saliva and there become ionised, until at equilibrium each un-ionised molecule has its associated ionised molecules, two ionised for each one un-ionised; and of course there will be one for each in plasma.

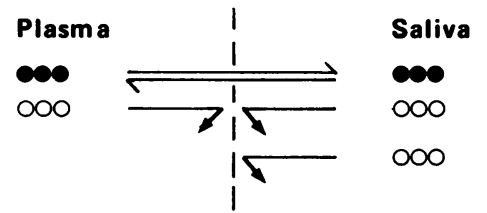

The result is that the total drug concentration is $50 \%$ higher in saliva than in plasma and the saliva/plasma concentration $(S / P)$ ratio is 1.5 . A basic drug would have the reverse ratio because it is less ionised at the higher $\mathrm{pH}$.

This effect of $\mathrm{pH}$ difference can be summed up by saying that for the horse, in the absence of other factors, the $S / P$ ratio for acidic drugs is greater than 1 , and for basic drugs less than 1 .

Similar effects occur throughout the body, an extreme case being alimentary absorption. The large pH difference between the very acid stomach contents and the blood favours the rapid absorption of acids, whereas bases are hardly absorbed at all until they pass into the duodenum, where the $\mathrm{pH}$ is much higher.

The actual S/P ratio given by an ionising drug is primarily dictated by the size of the $\mathrm{pH}$ difference between the two fluids. The dissociation or ionisation constant - the $\mathrm{pK}_{\mathrm{a}}$ - of the drug can also be very important, but it has little influence when it is more than one unit removed from either of the fluid $\mathrm{pH}$ values.

It is quite easy to calculate the theoretical $S / P$ ratio at equilibrium for an ionising drug using a simple formula derived from the Henderson-Hasselbalch equation. This is the formula for an acidic drug:

$$
S / P \text { ratio }=\frac{1+10 \mathrm{pH} \text { saliva }-\mathrm{pK}_{\mathrm{a}} \text { drug }}{1+10^{\mathrm{pH}} \text { plasma }-\mathrm{pK}_{\mathrm{a}} \text { drug }}
$$

With a basic drug the formula is similar, but the power terms are reversed to $\left(\mathrm{pK}_{\mathrm{a}}-\mathrm{pH}\right)$.

Parotid saliva from the ponies used at these laboratories has had a consistent $\mathrm{pH}$ of 7.9 , and it is intersting to compare the theoretical $\mathrm{S} / \mathrm{P}$ ratios using this value with those found in practice. For example an early experiment was with amphetamine, which being a basic drug should have an $S / P$ ratio less than 1 . The actual theoretical value is 0.3 and the experimental ratios were between 0.2 and 0.3 , which agreed fairly well.
When a drug is highly ionised in the blood, the theoretical $S / P$ ratio is unlikely to be reached because the amount of the drug in the diffusible form (i.e. the un-ionised drug) is so low. This was noticed by Rasmussen (1964) with sulphacetamide and by Borzelleca and Putney (1970) who considered that it might take several hours before a compound which was less than $1 \%$ unionised could reach a steady gradient across a membrane. Pedersen (1973) found that drugs were secreted into tears in a similar way as into saliva, but when he used benzylpenicillin the tears/plasma ratio was almost zero instead of the theoretical value of 0.6. He suggested the reason was its low $\mathrm{pK}_{\mathrm{a}}$ of $\mathbf{2 . 7}$ which means that less than $0.001 \%$ would have been un-ionised in blood.

During the work with chloral hydrate (Alexander, Horner et al., 1967) trichloroacetic acid, another of its metabolites, was also measured. The $S / P$ ratio was very low, always well below 0.1 , though the theoretical ratio at equilibrium is 3.2 ; but its $\mathrm{pK}_{\mathrm{a}}$ is as low as 0.7 , so that there is only about 1 part in a million which is unionised at plasma $\mathrm{pH}$ and it may have little chance of reaching equilibrium. In addition it may be up to $50 \%$ bound to plasma proteins (Souček, 1954).

\section{Protein Binding}

This is a second very important factor. Many drugs become bound to the proteins in plasma and in this bound form cannot pass into the saliva. A good example of this is the acidic drug phenylbutazone. The theoretical partition is strongly in favour of saliva, with an $S / P$ ratio of 3 , but when phenylbutazone was administered some years ago none at all was found. This was explained when measurements showed that at least $97 \%$ of the drug was bound to the plasma proteins; the analytical method used for phenylbutazone at that time was too insensitive to detect the minute amounts which were possibly present in the saliva.

When radiolabelled cortisol was given, the $S / P$ ratio was always very low, about 0.1 . Protein binding was again likely to be responsible; it has not been measured in the horse but in man normally about $92 \%$ of cortisol is bound (Daughaday \& Mariz, 1961). The same probably applies to dexamethasone, which gave a ratio of just over 0.3 and which is about $77 \%$ bound in man (Saunders, 1974).

\section{Fat Solubility}

In the body, the main barriers to drug transport are largely made up of lipid material, and if the drug is not very soluble in this its rate of transfer will be slowed down. Amberson and Höber (1932) showed this when they studied the transfer of non-electrolytes into cat saliva, and so did Rasmussen (1964) studying sulphonamide transfer in goats. Borzelleca (1968) concluded that low fat solubility was responsible for the fact that the 
concentration of glucose in dog saliva was only between 0 and $10 \%$ of the blood value. How fat solubility probably affects the S/P ratios of methyl xanthines is described below.

This effect explains in fact why ionised forms of drugs cannot pass into saliva, because they are generally not fat-soluble, whereas the un-ionised form of a drug usually is.

\section{Molecular Size}

Increasing molecular size is a further factor which reduces permeability, as was also shown by Amberson and Höber (1932) in the cat and by Burgen (1956) mainly in the dog. The effect of protein binding is just an extreme case of this, where the drug becomes part of a very large molecule which cannot cross at all.

\section{Rate of production of saliva}

Recent work at these laboratories has particularly concerned the methyl xanthines caffeine, theophylline and theobromine. They have all been reported frequently as doping agents, and theophylline and theobromine have been shown by Moss in an unpublished study to be important metabolites of caffeine in the horse.

Figure 3 is an experiment with theophylline. The mean ratio of saliva to plasma concentrations is close to 1 , but is not at all consistent. The plasma curve is fairly smooth, but the saliva concentrations are very variable.

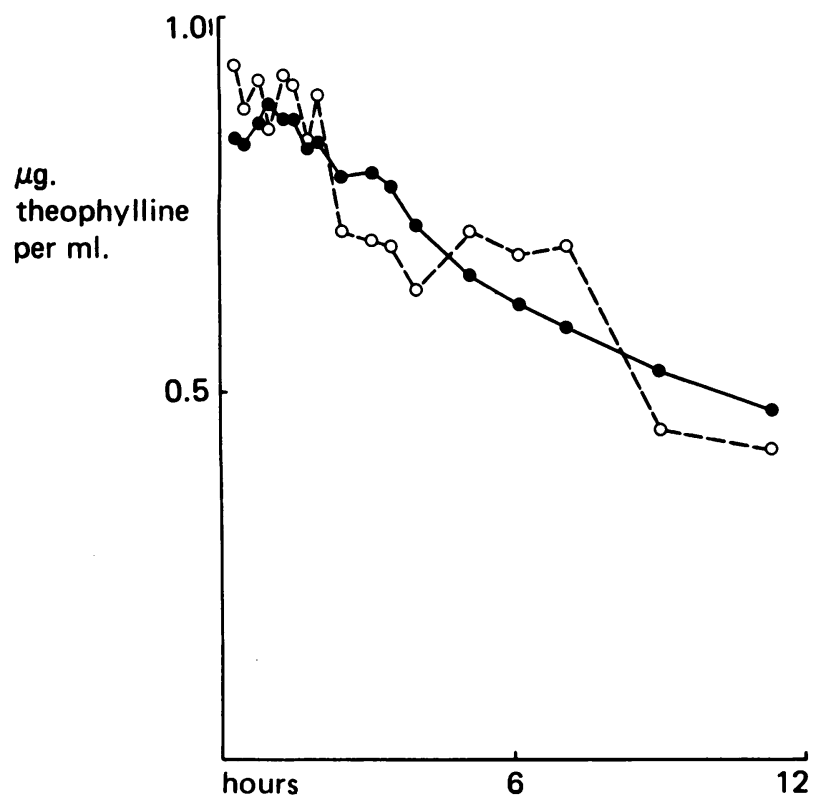

Fig. 3. Concentrations of theophylline in horse plasma (O) and parotid saliva $(O)$ after oral administration $10.65 \mathrm{mg}$ theophylline $/ \mathrm{kg}$ ).
When the S/P ratio was plotted against the rate of production of saliva the reason for this was seen. There was a clear correlation between the two - the faster the saliva flow the lower the S/P ratio. The other xanthines showed the same effect; the regression lines for all three compounds are given in Figure 4. Actual flow rates varied widely from less than 1 to over $30 \mathrm{ml} / \mathrm{min}$.

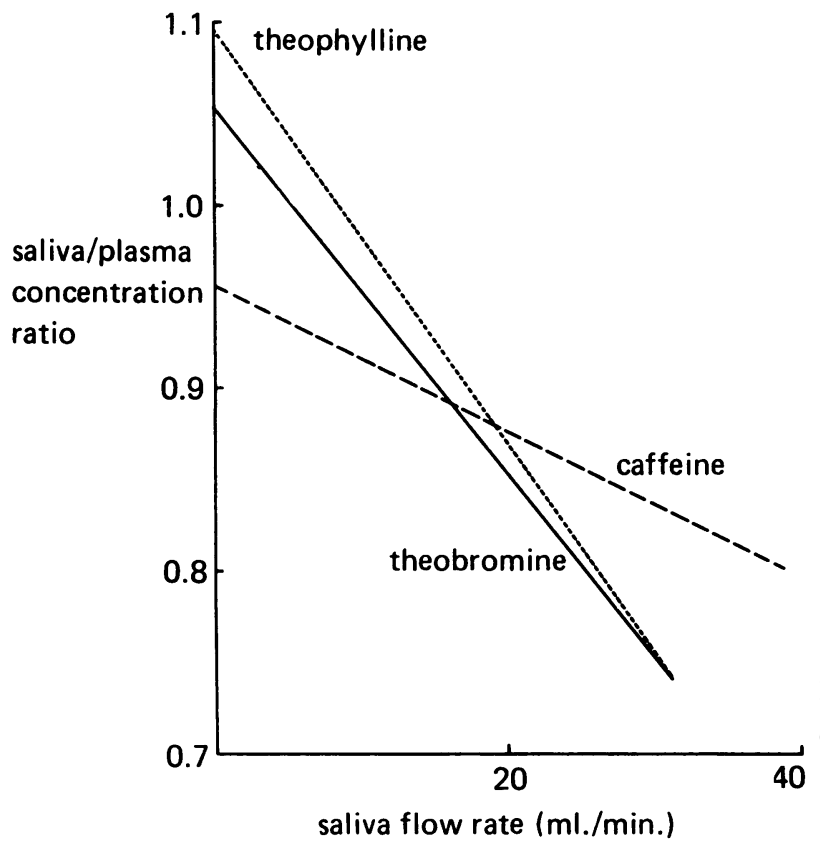

Fig. 4. Effect of rate of production of parotid saliva on saliva/ plasma concentration ratios of methyl xanthines.

Extrapolation of the theophylline and theobromine lines to zero flow rate gives $S / P$ ratios greater than 1 , which is to be expected as they are both weakly acidic. The actual ratios at zero flow rate are 1.09 and 1.05 respectively, which agree quite well with the theoretical values of 1.10 and 1.02 based on the $\mathrm{pK}_{\mathrm{a}}$ values measured by potentiometric titration. Caffeine is a neutral compound, but gives an $S / P$ ratio of less than 1 because a small amount of it is protein bound.

It seems clear that with all three xanthines equilibrium between saliva and plasma is only reached when the flow rate is almost zero, but the effect of increasing flow rate on the ratios is more pronounced with theophylline and theobromine. This is probably because of their relative fat solubility. Measurement of the partition ratio of the drugs between solvent and aqueous phases provided a measure of this and showed that caffeine is much more fat-soluble than the two dimethyl xanthines, so that caffeine transfer will be less hindered at high flow rates. 
The recent work outlined here is preliminary to more detailed studies to be published later; these will describe the metabolism in the horse of these three methyl xanthines (Moss) and their salivary secretion (Horner and Moss).

\section{Experiments with Other Drugs}

\section{Salicylate}

Work has just begun with sodium salicylate, using the drug with a ${ }^{14}$ carbon label on the carboxyl group. Figure 5 gives plasma and saliva radioactivity and the S/P ratios for a pilot experiment. At the beginning the ratio is about 0.3 but quickly drops to only 0.1 . There is an effect of saliva flow rate on the ratio, but it is only responsible for the small variations which are superimposed on the much larger change.
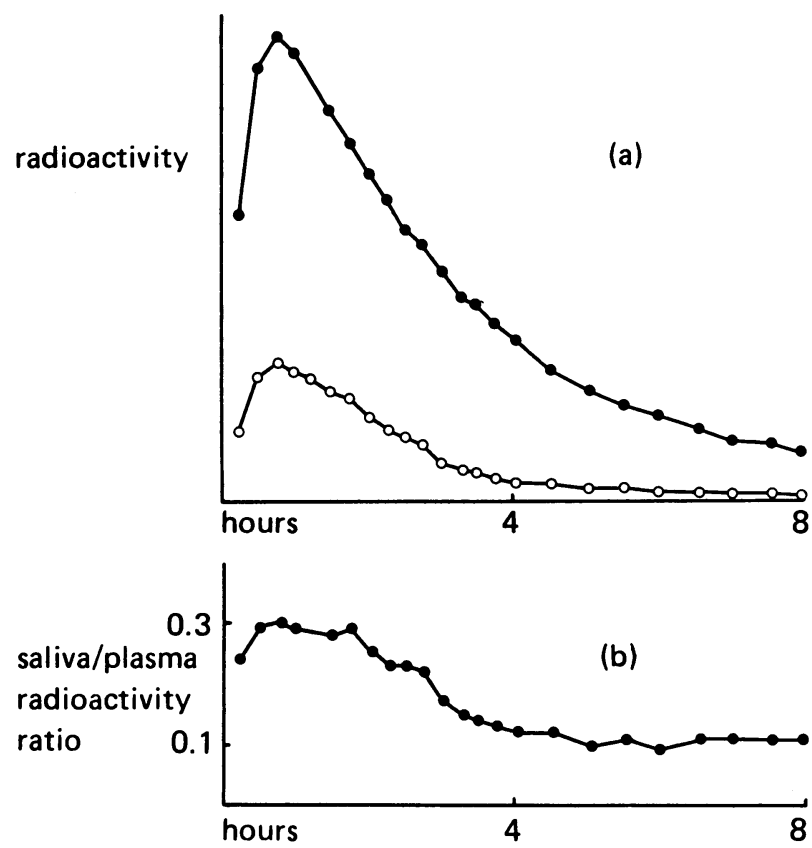

(N.B. No units given on 'radioactivity' axis - they are irrelevant).

Fig. 5. Oral administration of sodium salicylate $(40 \mathrm{mg} / \mathrm{kg})$ labelled with carbon-14.

a. Radioactivity in plasma (O) and parotid saliva (O). The peak of plasma radioactivity is equivalent to about $95 \mu \mathrm{g}$ sodium salicylate $/ \mathrm{ml}$.

b. Saliva/plasma radioactivity ratios.

The theoretical S/P ratio for the horse is 3.2 for salicylic acid. Protein binding measurements have shown that only $10 \%$ of it is free in plasma; this reduces the ratio to 0.32 which agrees well with the initial experimental value.
Salicylate is excreted very rapidly in the horse (Murdick \& Noonan, 1968; Schubert, 1967), only a small percentage being metabolised, mainly to glucuronides. These metabolites are likely to have a low fat solubility and therefore possibly cannot pass into saliva; their presence could well explain why the S/P ratio falls with time. This will be known when the metabolites in the samples have been separated from salicylate itself and have been identified and measured.

Comparison of results for ionising drugs in the horse with those in other species is often difficult because the $\mathrm{pH}$ of parotid saliva varies with species. In man it is much more acidic (pH 5.5-6.0 (23)) and in ruminants more alkaline $(\mathrm{pH}$ 8.2-8.4 in the goat (Rasmussen, 1964)). However, similar S/P ratios for salicylate of about 0.3 have also been reported in the rat (Putney \& Borzelleca, 1972) and the dog (Borzelleca \& Doyle, 1966) while the ratios are 0.3 to 0.6 in man (Leulier \& Sohier et al., 1946).

\section{Barbiturates}

The secretion of barbiturates into horse parotid saliva has been studied by Alexander and Nicholson (1968). They found saliva concentrations of phenobarbitone and pentobarbitone which were only about half and onefifth of the blood values respectively. Calculation of the theoretical ratios at equilibrium, allowing for protein binding, which they measured, gives figures about four greater, so other factors must be involved too. There may be a pronounced flow rate effect, or possibly the $\mathrm{pH}$ of the parotid saliva from their ponies was much lower than 7.9, though the latter seems unlikely because the experimental ponies here at Newmarket all produce saliva of the same $\mathrm{pH}$.

Rasmussen (1964) in his work with goats found saliva concentrations of barbiturates and some sulphonamides which agreed to within about $\pm 30 \%$ of the theoretical value, taking $\mathrm{pH}, \mathrm{pK}_{\mathrm{a}}$ and protein binding into account; other sulphonamides gave much lower ratios, which he attributed to the effects of their low fat solubility and low $\mathrm{pK}_{\mathrm{a}}$. These compounds have also been used by others who noticed the dependence of saliva drug concentrations on the $\mathrm{pK}_{\mathrm{a}}$ of the drug, but usually did not measure saliva pH. (e.g. Grüneisen \& Witzgall, 1974; Killmann \& Thaysen, 1955).

\section{Summary}

The work on the passage of drugs into horse saliva is still incomplete, but there is sufficient evidence to conclude that drugs are secreted passively into saliva by a process of diffusion, and that saliva concentrations follow the same time course as plasma concentrations, though the actual levels reached in saliva depend on 
several factors. These are listed in Table I. However, the problem still remains of how to obtain a larger sample by swabbing.

\section{TABLE I}

\section{Factors Controlling Drug Transport into Saliva}

Properties of the Drug

Properties of Saliva

whether acidic, basic or neutral

$\mathrm{pH}$

dissociation constant

flow rate

binding to plasma proteins

fat solubility

molecular size

\section{ATTEMPTS TO INCREASE THE SIZE OF SALIVA SAMPLES}

It is well known that psychological stimuli such as the sight, smell or even thought of food will increase salivation markedly in man (Langley, 1898) and the dog (Bernard, 1856), but Colin (1886) found no such effect on the salivary glands of the horse. No response to these stimuli has ever been elicited in the experimental ponies here, from either the parotid or mandibular secretions.

Chewing on inert substances will also induce salivation in man (e.g. Shannon, Suddick et al., 1974), but Colin (1886) and Scheunert and Trautmann (1921) state that there is no such response from the parotid gland of the horse. With the Newmarket ponies this has not been invariably true. Usually there was not the least secretion from the parotid papilla when the pony was encouraged to chew on a dry swab, for example, but occasionally the same pony has produced a good flow of saliva under apparently identical conditions. However, whether or not there was any response, the size of sample obtained by swabbing round the opposite (normal) papilla has still remained small. No change in the secretion from the mandibular gland has been seen in these experiments.

Taste stimulation, too, works well in man, especially using acid drops (Souček, 1954). Bernard (1856) found the same in dogs; weak acids placed in the mouth caused a copious secretion from all the glands, though salts were rather less effective and bitter compounds still less. Colin (1886) tried these with the horse but reported no effect on parotid salivation; Scheunert and Trautmann (1921) found the same, though one of their horses did produce parotid saliva when its mouth was irrigated with $2 \%$ hydrochloric acid.

Taste stimulation has recently been tried with the ponies at these laboratories. First the mouth was swabbed with a saline-soaked gauze. This was completely without effect during the swabbing, but when the swab was removed each pony began to lick its lips and swal- low, at the same time producing jets of parotid saliva. This continued for several minutes, the flow rate being about $5 \mathrm{ml} / \mathrm{min}$. Vinegar worked just as well and both caused a small increase in the mandibular secretion too. However, when this was repeated with a dry saltimpregnated gauze there was a good flow of parotid saliva from the very beginning of the swabbing; but again the saliva collected on this swab from the region of the opposite papilla was only about twice the normal volume.

It is possible to stimulate salivation in the horse by injection of pilocarpine (1) but the veterinary officers could hardly themselves inject a drug into a horse about to race!

When Claude Bernard carried out his wonderfully thorough study of salivation in various species in 1856, the only stimulus he found to parotid salivation in the horse was mastication of food; this has since been reaffirmed (Alexander, 1966; Colin, 1886; Scheunert \& Trautmann, 1921). It is certainly the best stimulus and the most reliable. It may be possible to make use of this, because it is not difficult to swab out a mouth which is full of food, while allowing the horse to continue chewing so that saliva production from the parotid gland does not stop. When this has been done, about three times the amount of saliva has been obtained as from an empty mouth, and with dry food contamination of the swab is only slight. Whether owners or trainers would object to their horses being given a mouthful of food before the race is another matter!

These experiments do give some promise of increasing the size of saliva samples if the right technique can be found. Apart from this, although some drugs are found in lower concentration in saliva than in other fluids, it nevertheless has definite practical advantages for pre-race testing.

\section{Acknowledgement}

The author is grateful to Dr. W. R. Cook of the Equine Research Station, Newmarket, for performing the explantation operations. 


\section{REFERENCES}

Alexander, F. 1966. A study of parotid salivation in the horse. J.Physiol., 184, 646-656.

Alexander, F., Horner, M. W. and Moss, M. S. 1967. The salivary secretion and clearance in the horse of chloral hydrate and its metabolites. Biochem. Pharmacol. 16, 1305-1311.

Alexander, F. and Nicholson, J. D. 1968. The blood and saliva clearances of phenobarbitone and pentobarbitone in the horse. Biochem. Pharmacol. 17, 203-210.

Amberson, W. R. and Höber, R. 1932. The permeability of mammalian salivary glands for organic non-electrolytes. J.cell.comp.Physiol. 2, 201-221.

Bernard, C. 1856. Leçons de physiologie expérimentale. 2. Baillière, Paris.

Borzelleca, F. 1968. Salivary excretion of glucose. Dog. J.oral Ther.Pharmacol. 4. 338-350.

Borzelleca, F. and Doyle, C. H. 1966. Excretion of drugs in saliva. Salicylate, barbiturate, sulfanilamide. J.oral Ther.Pharmacol. 3, 104-111.

Borzelleca, F. and Putney, J. W. 1970. A model for the movement of salicylate across the parotid epithelium. J.Pharmacol.exp. Ther. 174, 527-534.

Burgen, A. S. V. 1956. The secretion of non-electrolytes in the parotid saliva. J.cell.comp.Physiol. 48, 113-138.

Colin, G. 1886. Traite de physiologie comparée. 3rd edn. Baillière, Paris.

Daughaday, W. H. and Mariz, I. K. 1961. Corticosteroid-binding globulin: its properties and quantitation. Metabolism 10, 936-950.

Grüneisen, A. and Witzgall, H. 1974. Abhängigkeit der Speichelkonzentration körperfremder Stoffe von der Blutwasserkonzentration an dem Modell von fünf Sulfonamiden. Europ.J.clin.Pharmacol. 7, 77-79.

Killmann, S. A. and Thaysen, J. H. 1955. The permeability of the human parotid gland to a series of sulfonamide compounds, paraaminohippurate and inulin. Scand.J.clin.lab. Invest. 7, 86-91.

Langley, J. N. 1898. The salivary glands. In Textbook of Physiology, edited by E. A. Schäfer. Young J. Pentland, Edinburgh.

Leulier, A., Sohier, R. and Nouvel, G. 1946. Parotid saliva and sodium salicylate. C.r. Seanc. Soc. Biol. 140, 874-875.

Linde, P. 1932. The passage of ethyl alcohol into the parotid secretion in human beings. Arch.exp.Path. Pharmakol. $167,285-291$.

Murdick, P. W., Ray, R. S. and Noonan, J. S. 1968. Salicylic acid concentration in plasma and urine of medicated and non-medicated horses. Am.J. Vet. Res. 29, 581-585.

Pedersen, K. B. 1973. Excretion of some drugs in bovine tears. Acta pharmacol.toxicoit. 32, 455-466.

Putney, J. W. and Borzelleca, J. F. 1972. Mechanisms of ${ }^{14} \mathrm{C}$-salicylic acid excretion by the rat submaxillary gland. J.Pharmacol.exp. Ther. 182, 515-521.

Rasmussen, F. 1964. Salivary excretion of sulphonamides and barbiturates by cows and goats. Acta pharmacol. toxicol. 21, 11-19.

Saunders, L. 1974. The absorption and distribution of drugs. Baillière, Tindall. London. 
Scheunert, A. and Trautmann, A. 1921. Zum Studium der Speichelsekretion. I. Über die Sekretion der Parotis des Pferdes. Pflügers Arch.ges.Physiol. 192, 1-32.

Schmidt-Nielsen, B. 1946. The pH in parotid and mandibular saliva. Acta physiol.scand. 11, 104-110.

Schubert, B. 1967. Identification and metabolism of some doping substances in horses. II. Salicylic acid and its derivatives. Acta vet.scand. Suppl. 21. 16-41.

Shannon, I. L., Suddick, R. P. and Dowd, F. J. 1974. Saliva: composition and secretion. Monographs in Oral Science 2 edited by H. M. Myers, Karger, Basel.

Soǔek, B. 1954. Excretion of trichloroacetic acid. Pracovni LékaY̌ztvií 6, 277-278.

\section{DISCUSSION}

DONIKE: Have you measured the protein binding?

HORNER: Yes, by two methods; most of the measurements were done by ultra-filtration using a small cell, and Moss has done some protein binding measurements using ultra-centrifugation; that is the one we used for the salicylate measurements, the others have been done with the cell. to.

LAMBERT: Albumin is the main protein to which drugs bind except for cortisol which has its own protein to bind

JOUANY: For 10 years we used broken bits or Canadian bits for collecting saliva. The bit is quite large and as the horse masticates on the bit you get quite large amounts of saliva, 10 to 15 millilitres. We did not need to feed the horse.

HORNER: With parotid saliva, and I must emphasise this is what I have been working with, chewing on anything inert had absolutely no effect at all.

BLAKE: With regard to blood collections, in the United States in the region of 350,000 bloods have been collected in post- and pre-race situations. These are primarily from pacing and trotting animals but many, particularly in Kentucky, have been pure bred animals and to my knowledge little difficulty in blood collection has been experienced. This may not be the problem you seem to anticipate.

HORNER: We would much prefer to work with blood than saliva. Have you had no reaction from owners and trainers about the possible harmful effect of taking blood samples from their horses before racing?

BLAKE: We had some minor complaints in the early days. Over the past 3 or 4 years, to my knowledge, there have been no complaints, but these horses are primarily trotters and pacers.

STEELE-BODGER: Blake has made a relevant point here, there is all the difference in the world between the thoroughbred and the trotter. They are so used to being handled in every direction and there are so many contraptions around a trotter, even a trotter stallion.

MAYNARD: For years when we were doing salivas we kept track of saliva volumes and with wet saliva tests we were getting 15 to $25 \mathrm{ml}$ per horse. We also checked the difference between using plain distilled water and distilled water plus acetic acid, which was supposed to increase salivation, and found no difference whatsoever when using the acetic acid addition. During this period we did comparative tests between the urine and saliva positives and found only one saliva that gave a positive test compared with a large number of urines that gave positive tests. So saliva compared with urine for post-race testing was virtually valueless.

HORNER: If given the choice we would prefer urine for a pre-race test, if it is available. 


\section{EDITORIAL}

In this issue of the journal, the ancient origins of sports medicine are discussed in the paper by Don Masterson, who describes clinical facilities and sports injuries in the time of the ancient Greek civilisation. He points out that there was little development of sports medicine, or indeed of medicine of any kind, for some three thousand years. Scientific anatomy made large strides after the Renaissance, but physiology remained virtually a subject remote from experimental study until the close of the 19th century. With the beginning of the present century, physiology developed rapidly, taking advantage of related sciences such as electronics, chemistry, and pharmacology. Most effort was concentrated upon the study of the normal man and animal, and upon the infra-normal - the diseased patient. Very few people paid any attention to the study of the supra-normal, though such study could give a set of physiological parameters that could be regarded as the ideal for the fit man. Eventually a few physiologists extended their field of study to include the very fit, and the response of the very fit to severe exercise stresses that the untrained man could not undergo. An outstanding pioneer in this new field of exercise physiology is Professor Archibald Vivian Hill, working in the Physiology Department of University College, University of London, who celebrated his ninetieth birthday on September 16th 1976.

A. V. Hill's influence affected exercise physiologists everywhere, and his former students can be found world-wide; Michio Ikai, who died in Japan in 1972, Prof. R. Margaria of Milan, and many in Scandinavia. A very well-known colleague and admirer is Prof. Ernst Jokl, who submitted a manuscript for the issue of the journal, with the request that it be dedicated to Professor A. V. Hill. The Editorial Board decided that this number of the British Journal of Sports Medicine should be published in celebration of Professor Hill's birthday, and be devoted largely to topics in his own field of interest, the response of man to the stresses of exercise.

An appreciation of Professor Hill has been written by Ernest Hamley, who played a major part in producing this celebration number of B.J.S.M. Although not one of Hill's "academic children", he can be regarded as an "academic grandchild", who continued the work started in the early 1920's. "Academic great-grandchildren" such as Vaughan Thomas, Tom Reilly. Edward Winter and Bruce Davies have contributed papers from the U.K., and other of Hill's successors such as A. H. Ismail, and the Aerobics Institute team headed by Kenneth Cooper, together with their teams and associates, have contributed articles from across the Atlantic.

The editor regrets that there was a hold up in the production of No. 3 of the current volume, and this has in turn led to some delay in the production of this final issue of Volume 10 , No. 4. Much of the material has already been received for the first number of Volume 11, which we hope to publish in March 1977. The Editorial Board would appreciate articles submitted for later issues of Vol. 11, in time for proper refereeing and revision where necessary, to try to improve the standard of the journal but without making it too obstruse and unreadable by our membership.

We hope soon to publish the programme for 1977, and an advance notice is included in the journal concerning the B.A.S.M./F.I.M.S. course planned for Glasgow in late March - early April. As this may be the last journal issued before the course commences, we urge those interested to apply soon, and try to negotiate with their employing authorities for support (though in this present economic climate, there is little money available to train doctors, physiotherapists and P.E. teachers to do their job, even though they can get "the pill" for nothing and better social benefits in some cases than they can get when in employment).

As we go to press, we have received the first copy of "Physiotherapy in Sport", the new tri-annual journal of the Association of Chartered Physiotherapists in Sports Medicine. We welcome this journal, and congratulate the editor, Mr. John Cross, M.C.S.P., of 8 Trinfield Avenue, EXMOUTH, Devon, from whom copies can be obtained at 50 pence each.

\section{ERRATUM}

We draw readers' attention to an error in the caption to fig. 2 in Mrs. Marian Horner's article in Vol. 10 No. 3, page 134. The dose of ethanol/kg should of course be 1.14 GRAMMES, and not Milligrammes. We apologise for this error in proof reading. 